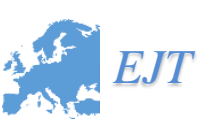

Research Article

\title{
THE EFFECTS OF ACID CONCENTRATION, ETCHING TEMPERATURE AND TIME ON THE SURFACE MORPHOLOGIES OF TI6AL4V
}

\author{
Melis YURDDASKAL ${ }^{1 *}$, Hülya DURMUŞ ${ }^{2}$
}

\begin{abstract}
Within this work, the effect of etching parameters on the surface morphology of Ti6Al4V alloy was investigated. For this purpose, different temperatures, different proportions of $\mathrm{HCl}-\mathrm{H}_{2} \mathrm{SO}_{4}$ acid mixtures and different etching times were used for the etching process. After etching, XRD analyses, SEM images and surface roughness values of the samples were presented. It was observed that increasing etching temperature facilitated the formation of pore structure on the surface, but after a certain temperature, the increasing temperature started to show negative effects. When all the microstructure images are considered, it is understood that acid concentration and etching time are effective parameters besides temperature difference.
\end{abstract}

Key words: Acid etching, Ti6Al4V, micromorphology, surface roughness

\section{Introduction}

Due to their superior compatibility with the body, titanium and its alloys are often used in implant materials. The most important factor determining the performance of Ti6Al4V implant material in the body is the surface properties. Among surface treatment methods, modifications of surface topography alterations are made to increase the response of cells to the implant.

Osseointegration is defined as the connection between the implant and bone at the microscopic level without a soft tissue component [1]. The speed and quality of osseointegration in titanium implants are also related to their surface properties [2]. Various studies have been conducted to improve osseointegration of the implants with different surface modifications. The main objective of implant manufacturers is to improve the surface properties of implants for protein adsorption, cell differentiation, adhesion and osseointegration [3]. Surface properties are based on the roughness [4-6], wettability [7] and chemical composition [8] of the implant surface. Implant surface modifications have been applied to titanium surfaces to increase biomechanical bonding between the implant and bone, to increase adhesion between the implant bone by enlarging the contact surface, and to increase osteoblast activity with faster formation of bone at the interface [9-12].

Recently, interest in chemically treated surfaces has increased in accelerating osseointegration [13]. Acidic etching is of potential importance for osseointegration and is known to increase peri-implant bone healing, particularly in the early stages. Also, there is no risk of contamination of the external implant surface in this technique. Acidic treatment also provides surface cleaning. The acidic etching has been shown to have a higher percentage of implant-bone contact, provide strong implant attachment,

1 Department of Mechanical Engineering, Manisa Celal Bayar University, Engineering Faculty, Manisa, Turkey, (melis.yurddaskal@cbu.edu.tr) (D) https://orcid.org/0000-0002-8774-3848

2 Department of Materials and Metallurgical Engineering, Manisa Celal Bayar University, Engineering Faculty, Manisa, Turkey, (hülya.durmus@cbu.edu.tr) (D) https://orcid.org/0000-0002-7270-562X 
and have a positive biological response in terms of bone apposition [14]. At the same time, acid selection plays an important role in the preparation of a rough titanium implant at process time. The surface prepared with hydrochloric acid is weaker than the surface prepared with sulfuric acid. Sulfuric acid $\left(\mathrm{H}_{2} \mathrm{SO}_{4}\right)$ followed by hydrochloric acid $(\mathrm{HCl})$ has been shown to give better results and show a similar texture to porous coatings, they are unlikely to surface dissolve, peel off and thus will not interact with a third wear particle in long-term fixation [15].

The aim of this study is to change the surface topography of the samples, polishing and chemical acidic etching were applied to the samples. As a result of these processes, it is aimed to obtain porous surfaces in accordance with the literature and phase structures, microstructures and roughness of these surfaces have been investigated.

\section{Experimental Details}

\subsection{Etching of the samples}

The samples with $16 \mathrm{~mm}$ diameter and $5 \mathrm{~mm}$ thickness were cut from a cylindrical Ti6A14V ELI (Grade 23) bar, and then mechanically grinded with 80 grit to 2000 grit SiC emery paper. After grinding process, the samples were cleaned ultrasonically in acetone, ethanol and deionized (DI) water for each $10 \mathrm{~min}$ and finally washed by distilled water. The mixture of $\mathrm{HCl}$ and $\mathrm{H}_{2} \mathrm{SO}_{4}$ mixed in equal proportions and different ratios were used in etching of the samples. Etching was carried out at room temperature $\left(25^{\circ} \mathrm{C}\right), 50,60,70$ and $80^{\circ} \mathrm{C}$ in order to observe the effect of temperature in etching process. Etching time was selected as 5 and $10 \mathrm{~min}$. The experimental stages of the samples and the etching parameters of the prepared samples were given in Figure 1 and Table 1, respectively.

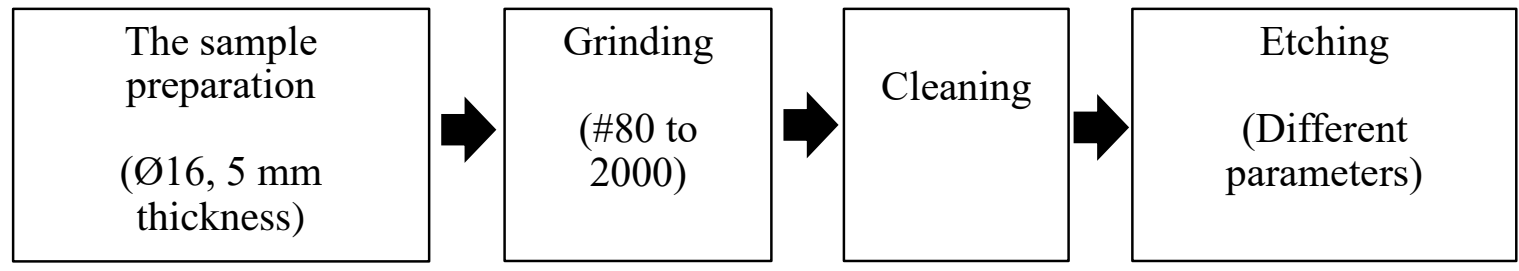

Figure 1. Experimental stages of the samples

Table 1. Etching parameters of them Ti6Al4V samples

\begin{tabular}{|c|c|c|c|c|c|c|c|c|c|c|}
\hline \multirow{2}{*}{$\begin{array}{l}\text { Etching } \\
\text { parameters }\end{array}$} & \multicolumn{5}{|c|}{ Group 1} & \multicolumn{3}{|c|}{ Group 2} & \multicolumn{2}{|c|}{ Group 3} \\
\hline & $25^{\circ} \mathrm{C}$ & $50^{\circ} \mathrm{C}$ & $60^{\circ} \mathrm{C}$ & $70^{\circ} \mathrm{C}$ & $80^{\circ} \mathrm{C}$ & $1: 1$ & $1: 2$ & $2: 1$ & $5 \mathrm{~min}$ & $10 \mathrm{~min}$ \\
\hline Temperature $\left({ }^{\circ} \mathrm{C}\right)$ & 25 & 50 & 60 & 70 & 80 & 70 & 70 & 70 & 70 & 70 \\
\hline Time $(\min )$ & 10 & 10 & 10 & 10 & 10 & 10 & 10 & 10 & 5 & 10 \\
\hline $\begin{array}{l}\text { Acid rate } \\
\left(\mathrm{HCl}: \mathrm{H}_{2} \mathrm{SO}_{4}\right)\end{array}$ & $1: 1$ & $1: 1$ & $1: 1$ & $1: 1$ & $1: 1$ & $1: 1$ & $1: 2$ & $2: 1$ & $1: 1$ & $1: 1$ \\
\hline
\end{tabular}

\subsection{Characterization}

XRD analysis for all samples were performed by Thermo Scientific ARL K-alpha model X-ray diffractometer. During the analysis, $\mathrm{Cu}-\mathrm{K} \alpha$ radiation $(1,5405 \AA)$ was used in the instrument, voltage and current values were set to $45 \mathrm{kV}$ and $44 \mathrm{~mA}$ respectively and experiments were performed with a 
scanning rate of $2 \% \mathrm{~min}$. All XRD analyses were performed in the range of $5^{\circ}<2 \theta<90^{\circ}$, and the range of $30^{\circ}<2 \theta<80^{\circ}$, which is the range of all characteristic peaks of the Ti6Al4V alloy, was plotted.

The microstructures of the surfaces were examined by using COXEM E30+ instrument at an accelerating voltage of 10-20 kV. Surface roughness tests were performed with Mitutoyo SJ-310 surface profilometer. The tests were performed using $4 \mathrm{~mm}$ scanning distance and $0.5 \mathrm{~mm} / \mathrm{s}$ speed. The average roughness $(\mathrm{Ra})$ and the peak-to-valley roughness $(\mathrm{Rz})$ values were taken from these tests. For each sample, five measurements were taken to calculate average results.

\section{Results and Discussions}

\subsection{Phase Analysis}

XRD analysis are given in Figure 2 in order to examine the samples etched at different temperatures, different acid concentrations and different periods. When all phase structures were examined, etching temperature, acid concentration and etching time did not cause any change in phase structure. There are two phases in the Ti6Al4V alloy structure, $\alpha \mathrm{Ti}$ (HCP) and $\beta \mathrm{Ti}$ (BCC). The phases present in the structure are $\alpha \mathrm{Ti}$ (JCPDS \# 44-1294) and $\beta \mathrm{Ti}$ (JCPDS \# 44 1288). The peaks on the graphs indicate which phases they belong to and which planes they correspond to in accordance with literature [16].

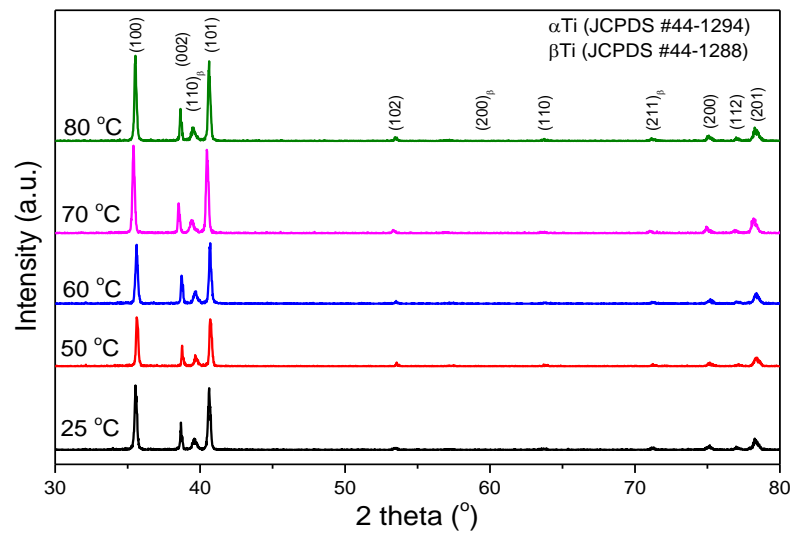

(a)

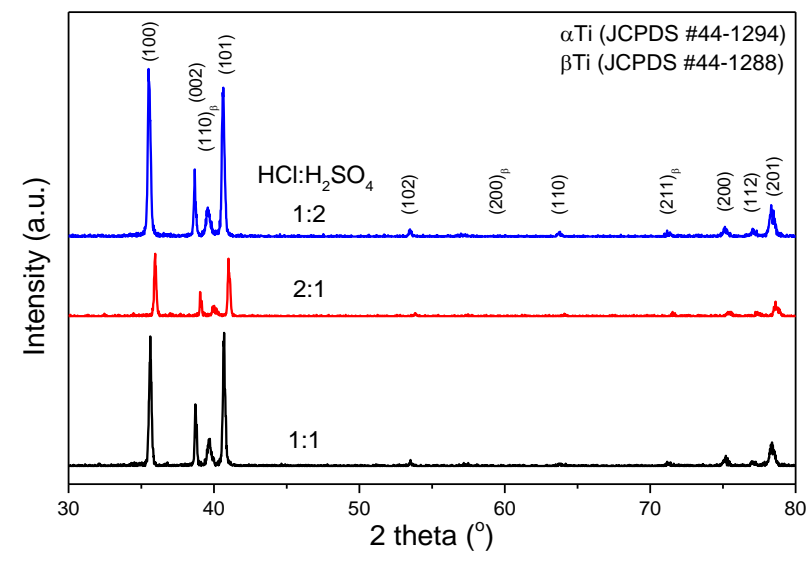

(b)

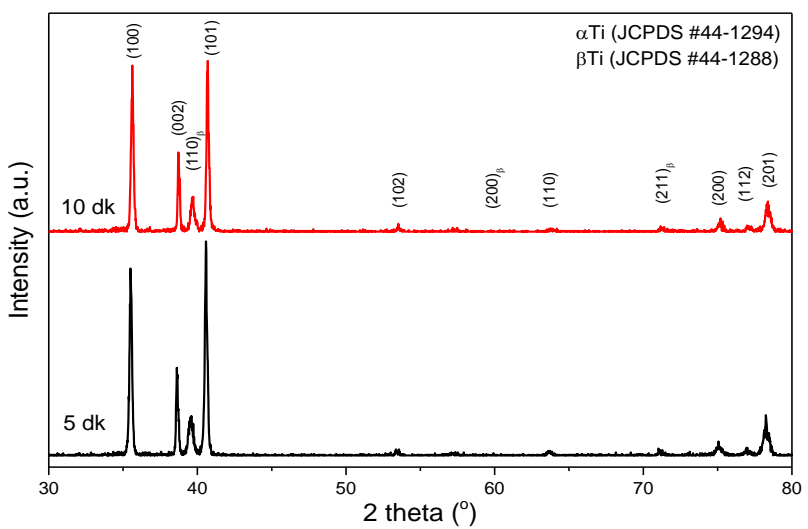

(c)

Figure 2. XRD patterns of the Ti6Al4V samples a) different temperatures b) different concentrations c) different times 


\subsection{Surface morphology}

Looking at the all SEM images in Figure 3, the morphologies of the samples etched at different temperatures are different from each other. This difference is caused by the different etch rate of the alpha and beta phases in the titanium alloy [17]. SEM images of samples etched between $25-60{ }^{\circ} \mathrm{C}$, the white regions indicate the presence of un-etched beta phase on the surface. So, it was found that the porous structure was not formed in terms of surface morphology in etching operations carried out at 25 , 50 and $60^{\circ} \mathrm{C}$.

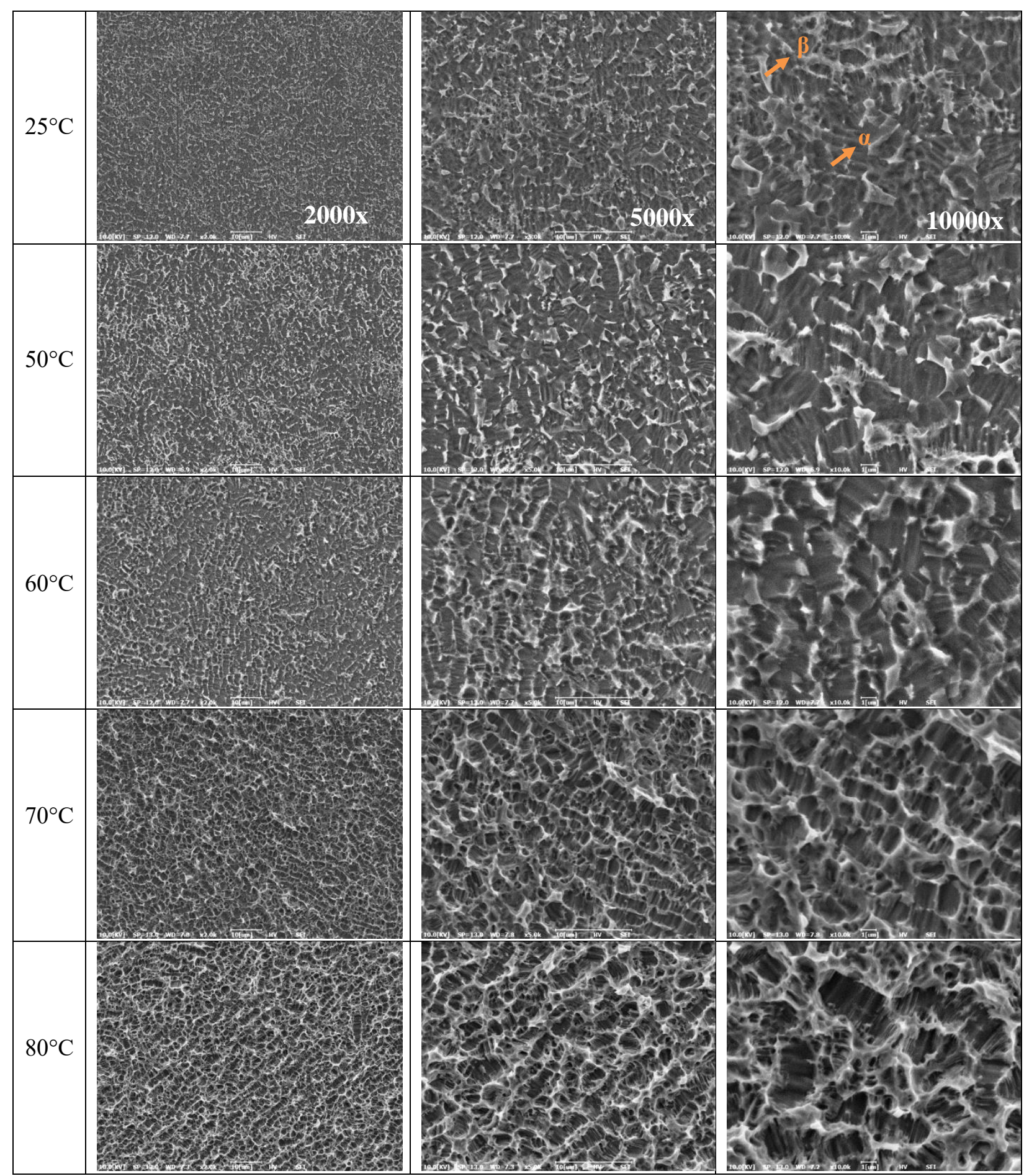

Figure 3. SEM images of the Ti6Al4V samples etched at different temperatures 
As the temperature increased, porous microstructures started to form on the alpha phase. Etching in the temperature range of 60 to $80^{\circ} \mathrm{C}$ is enough to evenly etch both phases without changing the porous structure [18]. Beta phase crystals were transferred to porous geometry in samples etched at 70 and 80 ${ }^{\circ} \mathrm{C}$. Thus, the alpha and beta phases on the surface are uniformly distributed. At $80{ }^{\circ} \mathrm{C}$, pore sizes were further increased compared to samples etched at $70{ }^{\circ} \mathrm{C}$. Therefore, it is understood from the microstructure images in Figure 3 that the temperature is a very important parameter for obtaining the porous structure. And then, it is clearly seen that porous structures start to form on the surface with increasing temperature [19].

The microstructures of the samples etched with different concentration are shown in Figure 4. As shown in Figure 4, it was observed that more uniform and homogeneous pore structures were formed in samples where 1: $1\left(\mathrm{HCl}: \mathrm{H}_{2} \mathrm{SO}_{4}\right)$ and 1: 2 acid concentrations were applied. The porous structure was almost never formed in the sample etched at a 2: 1 acid concentration. It can be concluded that $\mathrm{H}_{2} \mathrm{SO}_{4}$ used in etching process is more effective on beta phases than $\mathrm{HCl}$ acid [20].

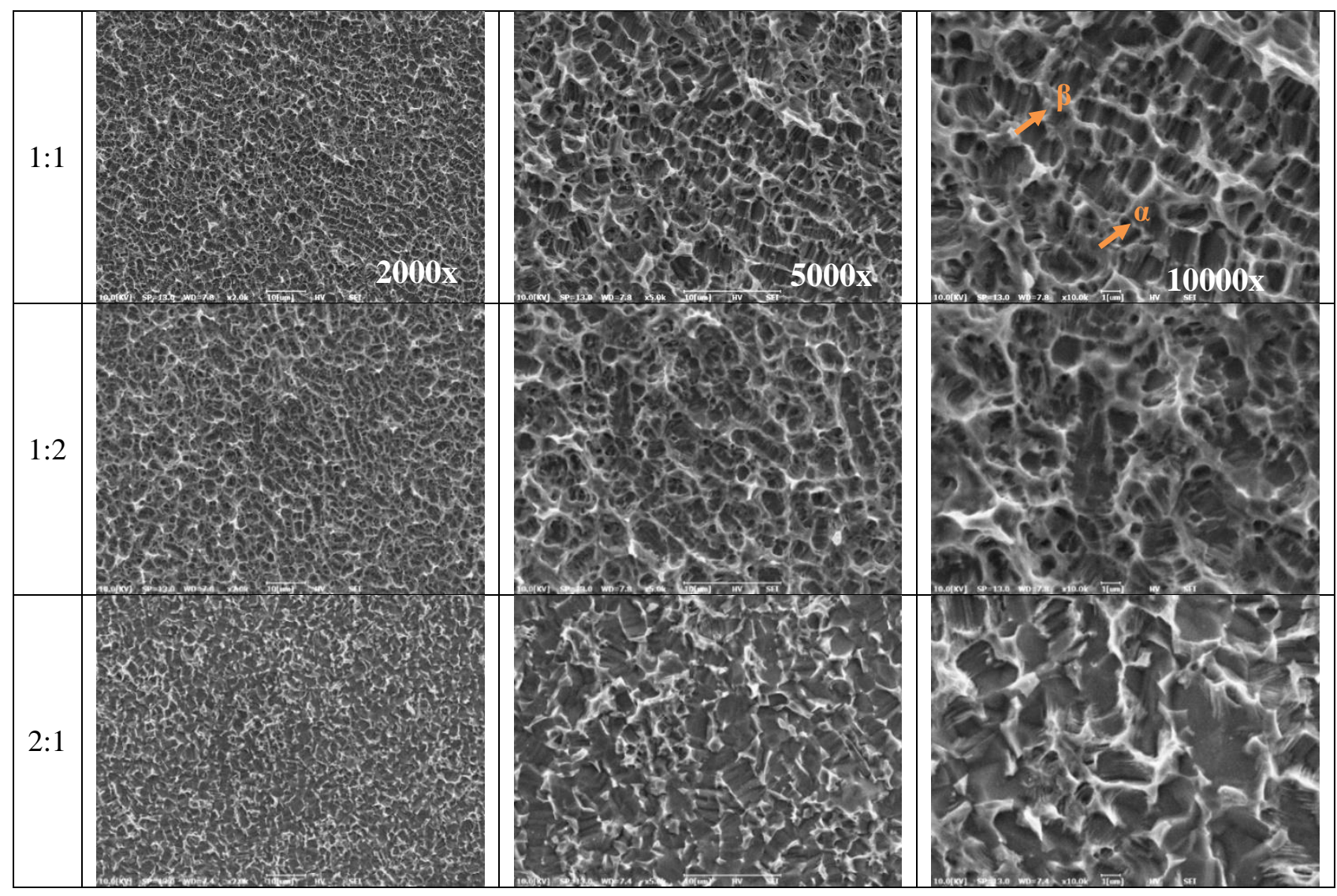

Figure 4. SEM images of the Ti6AI4V samples etched with different acid concentrations ( $\left.\mathrm{HCl}: \mathrm{H}_{2} \mathrm{SO}_{4}\right)$

Figure 5 shows that the etching time of 5 minutes is not sufficient for pore formation on the surface. While the lamination and layered microstructure were obtained in the samples which were etched for 5 minutes, regular pore structures started to be formed by increasing the etching to 10 minutes. When all the microstructure images are considered, it is understood that acid concentration and etching time are effective parameters besides temperature difference [21]. 


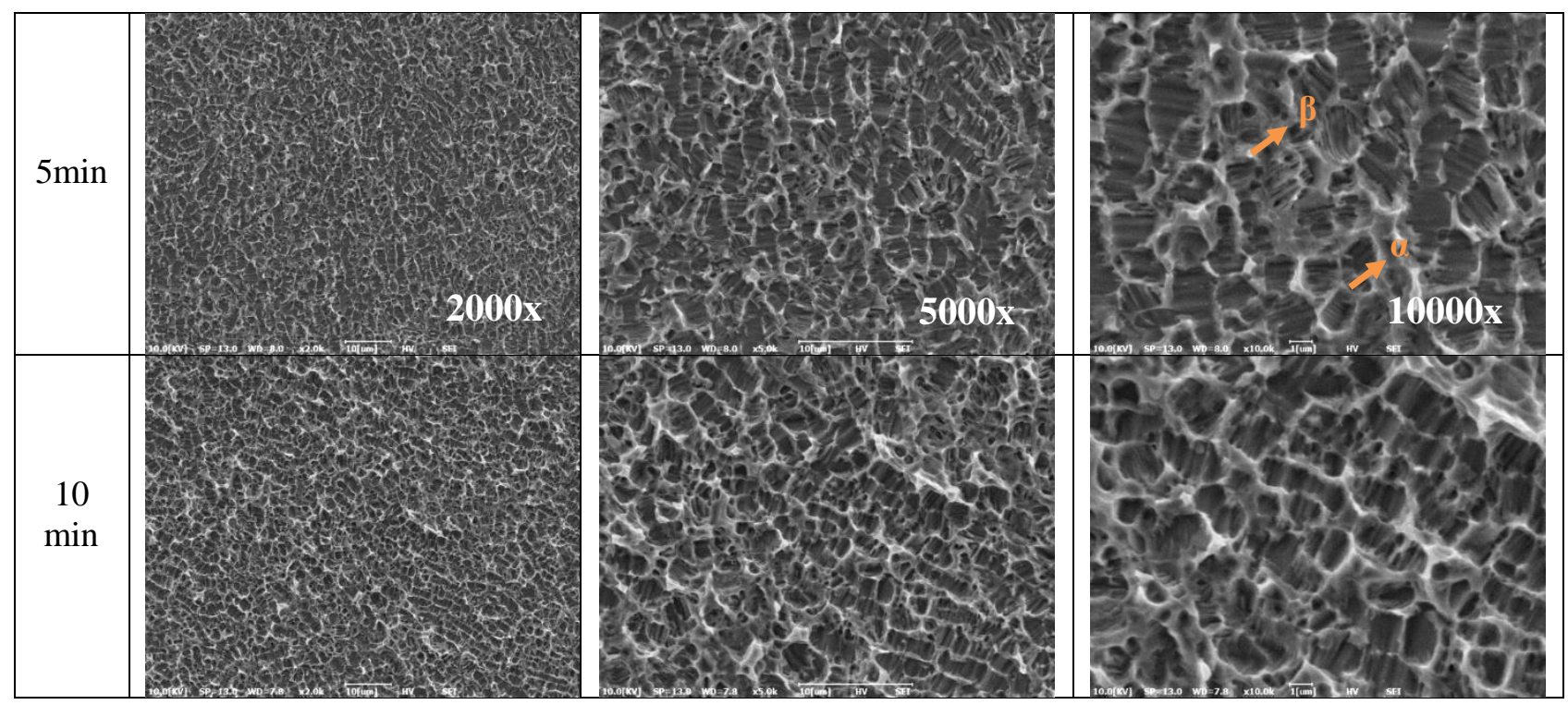

Figure 5. SEM images of the Ti6Al4V samples etched with different times

\subsection{Surface Roughness}

Table 2 shows the arithmetic average of the absolute values of all points of the profile ( $\mathrm{Ra}$ ) and the arithmetic average of the maximum peak to valley height of the roughness values of five successive sampling sections over the filtered profile (Rz).

Table 2. Surface roughness values of the Ti6Al4V samples

\begin{tabular}{|c|c|c|c|c|c|}
\hline \multirow[b]{2}{*}{ Groups } & \multicolumn{3}{|c|}{ Etching Parameters } & \multirow{2}{*}{$\begin{array}{c}\mathrm{Ra} \\
(\mu \mathrm{m})\end{array}$} & \multirow[b]{2}{*}{$\begin{array}{l}\mathrm{Rz} \\
(\mu \mathrm{m})\end{array}$} \\
\hline & $\begin{array}{c}\text { Temperature } \\
\left({ }^{\circ} \mathrm{C}\right)\end{array}$ & $\begin{array}{c}\text { Concentration } \\
\left(\mathrm{HCl}: \mathrm{H}_{2} \mathrm{SO}_{4}\right)\end{array}$ & $\begin{array}{l}\text { Time } \\
(\min )\end{array}$ & & \\
\hline \multirow{5}{*}{1} & 25 & $1: 1$ & 10 & $0.22 \pm 0.0204$ & $1.45 \pm 0.088$ \\
\hline & 50 & $1: 1$ & 10 & $0.27 \pm 0.0147$ & $1.79 \pm 0.156$ \\
\hline & 60 & $1: 1$ & 10 & $0.26 \pm 0.0102$ & $1.83 \pm 0.087$ \\
\hline & 70 & $1: 1$ & 10 & $0.31 \pm 0.0206$ & $2.04 \pm 0.114$ \\
\hline & 80 & $1: 1$ & 10 & $0.33 \pm 0.0233$ & $2.27 \pm 0.143$ \\
\hline \multirow{3}{*}{2} & 70 & $1: 1$ & 10 & $0.31 \pm 0.0206$ & $2.04 \pm 0.114$ \\
\hline & 70 & $1: 2$ & 10 & $0.29 \pm 0.0117$ & $2.00 \pm 0.167$ \\
\hline & 70 & $2: 1$ & 10 & $0.23 \pm 0.0279$ & $1.58 \pm 0.148$ \\
\hline \multirow{2}{*}{3} & 70 & $1: 1$ & 5 & $0.26 \pm 0.0080$ & $1.56 \pm 0.034$ \\
\hline & 70 & $1: 1$ & 10 & $0.31 \pm 0.0206$ & $2.04 \pm 0.114$ \\
\hline
\end{tabular}

Looking at the measurement results, it has been seen that the surface roughness tends to increase with increasing temperature. In the second group of samples, in which the acid concentration parameter was discussed, the maximum surface roughness was observed to be obtained in samples that were etched at one-to-one concentration. Also, the prolonged etching time caused an increase in roughness [22]. As a result, it was found that the micron scale hilly rough structure formed by etching significantly improved the roughness of the Ti6Al4V surface. 


\section{Conclusions}

In this study, the effect of etching parameters such as temperature, acid concentration and time on the surface of the Ti6Al4V alloy was investigated. The following conclusions can be summerized:

- Low temperatures were not effective in forming the pore structure on the Ti6A14V samples surfaces. The etching temperature were $70^{\circ}$ and $80^{\circ}$, where the alpha-beta phase balance was established, and the phases were distributed on the surface uniformly.

- $\mathrm{H}_{2} \mathrm{SO}_{4}$ used in etching process was more effective than $\mathrm{HCl}$ acid on beta phases for obtaining porous structure on the surface.

- When the SEM images of samples that were etched with an equal concentration of acid were examined together with the surface roughness, it can be said that the roughest structure was formed in these samples.

\section{Acknowledgment}

The authors thank to MCBU Coordination Department of Scientific Research Projects (Project: CBUBAP 2017-177) for their financial support. In addition, the financial support supplied by The Scientific and Technological Research Council of Turkey (TUBITAK, Turkey) [Grant No. 2228-B.2015-1] for the first author was gratefully acknowledged.

\section{References}

[1] Götz, H.E., Müller, M., Emmel, A., Holzwarth, U., Erben, R.G., Stangl, R.(2004).Effect of surface finish on the osseointegration of laser-treated titanium alloy implants. Biomaterials, 25(18), pp. 4057-4064.

[2] Uchida, M., Oyane, A., Kim, H.-M., Kokubo, T., and Ito, A. (2004). Biomimetic coating of lamininapatite composite on titanium metal and its excellent cell-adhesive properties. Advanced Materials, 16(13), pp. 1071-1074.

[3] Dai, X., Zhang, X., Xu, M., Huang, Y., Heng, B.C., Mo, X., Liu, Y., Wei, D., Zhou, Y., Wei, Y., Deng, X., Deng X. (2016). Synergistic effects of elastic modulus and surface topology of Ti-based implants on early osseointegration. RSC Advances, 6, pp. 43685-43696.

[4] Dhaliwal, J.S., Rahman, N.A., Knights, J., Ghani, H., Junior, R.F.A. (2019). The effect of different surface topographies of titanium implants on bacterial biofilm: a systematic review. SN Applied Sciences, 1, Article Number: 615.

[5] Zinger, O., Anselme, K., Denzer, A., Habersetzer, P., Wieland, M., Jeanfils, J., Hardouin, P., Landolt, D. (2004). Time-dependent morphology and adhesion of osteoblastic cells ontitanium model surfaces featuring scale-resolved topography. Biomaterials, 25, pp. 2695-2711.

[6] Kelly, C.N., Evans, N. T., Irvin, C.W., Chapmand, S.C., Galle, K., Safranskif, D.L. (2019). The effect of surface topography and porosity on the tensile fatigue of 3D printed Ti-6Al-4V fabricated by selective laser melting. Materials Science \& Engineering C, 98, pp. 726-736.

[7] Mendonça, G., Mendonça, D.B.S., Araga o, F.J.L., Cooper, L.F.(2008). Advancing dental implant surface technology - From micron to nanotopography. Biomaterials, 29, pp. 3822-3835. 
[8] Guéhennec, L.L., Soueidan, A., Layrolle, P., Amouriq, Y. (2007). Surface treatments of titanium dental implants for rapid osseointegration. Dental Materials, 23 (7), pp. 844-854.

[9] Degidi, M., Petrone, G., Iezzi, G., Piattelli, A. (2003). Bone contact around acid etched implants: a histological and histomorphometrical evaluation of two human retrieved implants. Journal of Oral Implantology, 29 (1), pp. 13-18.

[10]Pippenger, B. E., Rottmar, M., Kopf, B.S., Stübinger, S., Torre, F.H.D., Berner, S., Weber, K. M. (2018). Surface modification of ultrafine-grained titanium: Influence on mechanical properties, cytocompatibility, and osseointegration potential. Wiley Clinical Oral Implants Research, https://doi.org/10.1111/clr.13396

[11]Suzuki, G., Hirota, M., Hoshi, N., Kimoto, K., Miura, H., Yoshinar, M., Hayakawa, T., Ohkubo, C. (2019). Effect of Surface Treatment of Multi-Directionally Forged (MDF) Titanium Implant on Bone Response, Metals, 9(2), Article Number: 230.

[12]Souza, J.C.M., Sordi, M.B., Kanazawa, M., Ravindran, S., Henriques, B., Silva, F.S., Aparicio, C., Cooper, L.F. (2019). Nano-scale modification of titanium implant surfaces to enhance osseointegration. Acta Biomaterialia, 94, pp. 112-131.

[13]Bornstein, M.M., Lussi, A., Schmid, B., Belser, U.C., Buser, D. (2003). Early loading of nonsubmerged titanium implants with a sandblasted and acid-etched (SLA) surface: 3-Year results of a prospective study in partially edentulous patients. International Journal of Oral and Maxillofacial Implants, 18 (5), pp. 659-666.

[14]Jungner, M., Lundqvist, P. Lundgren, S. (2005). Oxidized titanium implants (Nobel Biocare ${ }^{\circledR}$ TiUnite $^{\mathrm{TM}}$ ) compared with turned titanium implants (Nobel Biocare ${ }^{\circledR}$ mark III ${ }^{\mathrm{TM}}$ ) with respect to implant failure in a group of consecutive patients treated with early functional loading and two stage protocol. Clinical Oral Implants Research, 16 (3), pp. 308-312.

[15]Parekh, R. B., Shetty, O., Tabassum, R. (2012). Surface modifications of endosseous dental implants. International Journal of Oral Implantology \& Clinical Research, 3 (3), pp. 116-121.

[16]Hammood, A. S., Thair, L., \& Ali, S. H. (2019). Corrosion Behavior Evaluation in Simulated Body Fluid of a Modified Ti-6Al-4V Alloy by DC Glow Plasma Nitriding. Journal of Bio-and TriboCorrosion, 5(4), 100.

[17]Hung, K.Y., Lin, Y.C., and Feng, H.P. (2017). The effects of acid etching on the nanomorphological surface characteristics and activation energy of titanium medical materials. Materials, 10, pp. 11641178 .

[18]Chauhan, P., Koul, V., and Bhatnagar, N. (2019). Effect of acid etching temperature on surface physiochemical properties and cytocompatibility of Ti6A14V ELI alloy. Materials Research Express, 6(10), Article Number:105412.

[19]Balla, V. K., Soderlind, J., Bose, S., \& Bandyopadhyay, A. (2014). Microstructure, mechanical and wear properties of laser surface melted Ti6Al4V alloy. Journal of the mechanical behavior of biomedical materials, 32, 335-344.

[20]Zhang, D. G., Cheng, H. M., Wang, Y. J., \& Ning, C. Y. (2011). Effect of different acid treatment on surface characteristics of titanium alloy. In Materials Science Forum (Vol. 694, pp. 490-496). Trans Tech Publications Ltd. 
[21]Adamek, G., \& Jakubowicz, J. (2010). Mechanoelectrochemical synthesis and properties of porous nano-Ti-6Al-4V alloy with hydroxyapatite layer for biomedical applications. Electrochemistry communications, 12(5), 653-656.

[22]Variola, F., Yi, J. H., Richert, L., Wuest, J. D., Rosei, F., \& Nanci, A. (2008). Tailoring the surface properties of Ti6Al4V by controlled chemical oxidation. Biomaterials, 29(10), 1285-1298. 